\title{
Dags in sheep; a look at faeces and reasons for dag formation
}

\author{
G.C. WAGHORN ${ }^{1}$, N.G. GREGORY ${ }^{2}$, S.E. TODD ${ }^{3}$ and R. WESSELINK ${ }^{4}$ \\ ${ }^{1}$ AgResearch Grasslands, Private Bag 11008, Palmerston North \\ ${ }^{2}$ MIRINZ, PO Box 617, Hamilton \\ ${ }^{3}$ Massey University, Private Bag 11222, Palmerston North \\ ${ }^{4}$ AgResearch Ruakura, Private Bag 3123, Hamilton
}

\begin{abstract}
Dags represent a major cost to sheep farmers, in both monetary terms and because of the stress associated with flystrike. Historically, the incidence of dags has been attributed in large part to worm burdens, but other causes may be more important, viz parasite larval challenge, fungal endophyte and selection of sheep for resistance to worms. These and other factors associated with the incidence of dags are summarised, together with variations in faecal types (physical and chemical composition) which affect their capacity for adhesion to wool. Much of these data emphasise the importance of differences or changes in intestinal function being responsible for the loose and gooey faeces which develop into dags. Flystrike is strongly correlated with dags, and this scenario cannot be tolerated in a country claiming to produce good, clean food.
\end{abstract}

Keywords: dags, diarrhoea, endophyte, faeces, flystrike, parasitism, sheep

\section{Introduction}

Dags are almost synonymous with sheep in New Zealand. They represent a significant problem for sheep farmers (Mackereth 1983) because dags need to be removed, are hard to prevent and are associated with flystrike. Despite their prevalence and the current research which is examining means for controlling intestinal parasites and fungal endophytes (both of which affect dags) and flystrike, there are few data dealing with the incidence of dags, frequency of dagging and their cost to farming. If these were available, especially on a regional basis, researchers would better understand the relationships between the factors contributing to and consequent upon dags and develop integrated management systems to reduce these costs for the farmer. Comparisons might be made with sheep producers in countries with climates similar to New Zealand (United Kingdom) and contrasting environments (Australia, South Africa). Unfortunately few statistics appear to be available concerning dags nationwide, and this paper will present some best guesses, based on comments from colleagues, but with the clear intent that others challenge and correct our assumptions (Table 1) by acquisition of data.

Flystrike is a major component of the cost of dags. Leathwick \& Atkinson (1995) reported a 0.97 correlation between the two and this association is consistent with the predominance of strike on the hind quarters of sheep, especially lambs (Heath \& Bishop 1995; Leathwick \& Atkinson 1996). The frequent use of anthelmintic drenches as a means to reduce the incidence of dags (e.g., Pullman et al. 1991; Larsen et al. 1994), even if dags were not caused by nematodes must be partly responsible for increasing drench resistance.

What is a dag? I will define it as faecal material accumulating around the anus (breech) of sheep. Dags are rare in goats, but in sheep they accumulate below, to the sides and even above the anus. The development of dags first requires some faeces to adhere to wool, but this is only the initial step in accumulation. The principal factor in dag development is the adhesion of faeces to faeces already adhering to the wool. Dags can cover the whole rear end of a sheep, and even become dried without falling off. One consequence of the prevalence of dags is that they have entered the vernacular, the phrase "to rattle your dags", meaning to hurry up. Of course the initial adhesion of faeces to wool is closely aligned to another aphorism concerning vigorous sticking of substances "like faeces to a (woollen) blanket".

Given that within any flock some sheep have dags whilst others have none, it is clear that some aspect of individual sheep affects the initiation and accumulation of dags. When exploring the variation in the incidence of dags, it is essential to adopt a multifaceted view. For example, sheep differences may include sex, tail length, wool type and length, anatomy of the anus and surrounding regions as well as physiological differences. Physiological factors which we believe may be important include large bowel function, especially the time taken for digesta to pass through the caecum, centripetal and centrifugal coils of the colon and the rectum because transit is likely to affect absorption of moisture. Sheep rarely produce liquid (diarrhoea) faeces, but gooey, sticky, semi-fluid faeces are common. Other types include faeces formed into stools, faeces formed into pellets which are compressed into stools, and finally free pellets which are characteristic of healthy sheep. 
The form of faeces will affect its ability to accumulate into dags, and faecal form is most likely affected by the rate at which digesta passes through the large intestine, together with intestinal function. We suspect a rapid transit through the large intestine might be facilitated by the presence of worms, larval challenge, fungal endophyte and high levels of voluntary intake by lactating sheep or animals given lush, highly digestible pasture.

\section{Digestion and faeces composition}

Faeces comprise undigested feed components, bacteria, endogenous secretions and water. The proportions of these constituents will be affected by feed type and level of intake, both of which influence residence time in the digestive tract. A rapid passage of digesta will reduce degradation of fibre components in the rumen and a rapid passage through the large intestine will limit the potential for mineral and water absorption, resulting in faeces with a high moisture content. Feed quality will also affect the extent of microbial (bacterial, protozoal, fungal) activity in the rumen whilst some dietary constituents may have indirect effects on faeces composition. Examples include condensed tannins, present in Lotus spp, sulla and dock which appear to increase mucus secretion (Waghorn et al. 1999) but also reduce the incidence of dags (Leathwick \& Atkinson 1995; Niezen et al. 1998). Table 2 summarises the chemical composition of faeces from sheep fed contrasting diets, and shows a two-fold variation in concentration of major constituents and a larger variation in concentration of individual elements.

Our study of the mechanisms by which faeces adhere to wool shows that pelleted faeces are unable to form dags. If sheep produced pelleted faeces at all times, we believe dags would not occur (except perhaps if sheep lay on wet faeces). Hence an understanding of the methods by which sheep form pellets, as distinct from stools or diarrhoea, would provide a physiological basis for understanding and ultimately controlling the occurrence of dags.

Irrespective of diet, the secretion of saliva, electrolytes and other endogenous substances result in quite fluid contents throughout most of the alimentary tract. Rumen contents comprise $84-90 \%$ water and more liquid is added to the abomasum (true stomach) and proximal intestine (duodenum) where the digesta comprises $94-97 \%$ water. The small intestine of a sheep is $15-20 \mathrm{~m}$ in length, and at its distal point where it enters the caecum and large intestine, the digesta contains $88-92 \%$ water and $8-12 \%$ dry matter (Waghorn, unpublished data). In order that pellets may be formed at or distal to the flexure between the centripetal and

Table 1 Costs and consequences of dags in the New Zealand flock ${ }^{\mathrm{a}}$ (per annum). Flystrike costs have been included because dags increase the incidence and severity of strike.

Incident Costs (\$ millions)

1. Need for crutching or dagging, including lambs:

$50 \%$ of national flock; 35 million at $\$ 0.3$ each

2. Costs of flystrike ${ }^{\text {b: }}$

Farmers report 5-10\% of the flock are struck and treated; costs here are based on $7 \%$ of 1999 sheep numbers

loss of premium for lambs (\$10 each)

loss of wool from struck area (\$0.7 each)

cost of chemical and labour to treat struck animals (\$1 each)

Lamb and ewe deaths, not treated; $0.5 \%{ }^{c}$ of flock at $\$ 30$ each

3. Effect of dags on performance, utilization of feeds, growth, etc. (related to costs of worms, endophyte, flystrike, etc.)?

4. Cost to farmer for checking stock, preventative dipping and stress associated with a very unpleasant task

5. Cost to country through use of anthelmintic drenches to counter dagginess and consequent development of drench resistance

6. Ethical costs of growing sheep knowing that flystrike is inevitable

7. Consequences of not dagging:

- Reduction in fleece value by stain or chip contamination

- Reduction in lambing percentages

- Greater losses to flystrike

- International trade bans based on ethics of good husbandry

- Loss of sheep industry

a Flock numbers (millions) lambs, 36; overwintered, 45, total sheep 70.

b K. Geenty, R. Kidd pers comm.; Heath (1994).

c Probably conservative estimate. 
Table 2 Digestibility and faeces composition (\% of dry matter; DM) from sheep fed contrasting diets ${ }^{\mathrm{a}}$. N = 5-6 animals/feed type. Data from Wesselink et al. (1995).

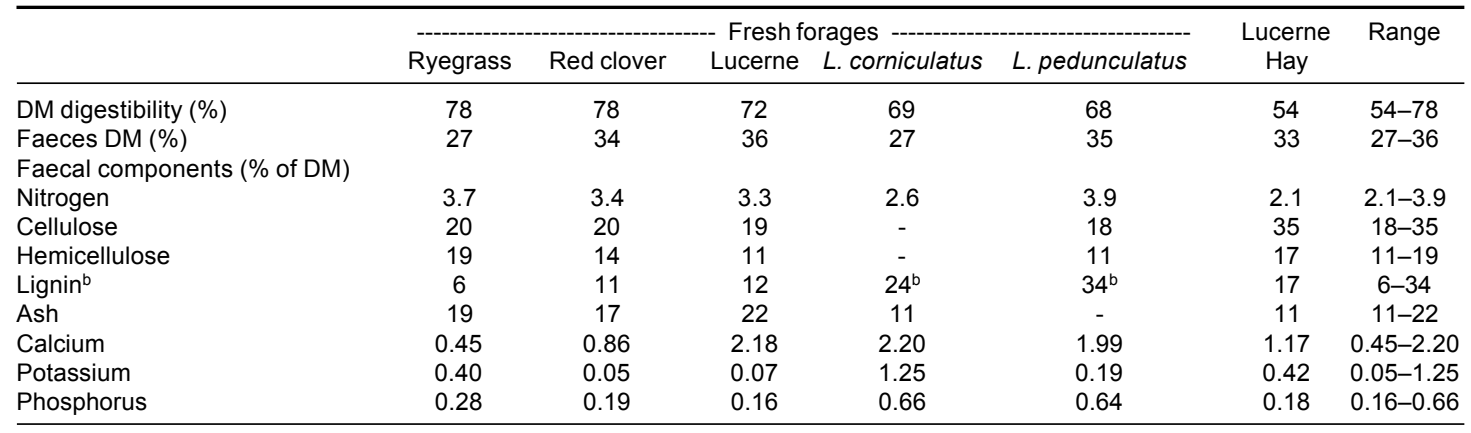

a Sheep drenched to remove worms and fed indoors in crates at 860-980 g DM/day (ryegrass, red clover, lucerne and lucerne hay) and 1200-1400 g DM/day (Lotus spp.).

b Lignin component includes condensed tannins.

centrifugal coils of the colon, the water content of digesta must be reduced to $80 \%$ (or less). Failure to reduce the moisture content of this digesta during passage through the large intestine will result in either stools or diarrhoea, both of which are potentially able to adhere to wool and to existing faeces thereby developing into dags.

The structure and function of the large intestine has been reviewed by Ulyatt et al. (1975). In brief, the large intestine of the sheep contains $10-20 \%$ of the total gut contents, much of which is located in the caecum. The caecum is a blind sac and digesta may be held here for several hours and undergo further microbial digestion. A substantial mucous secretion occurs throughout the large intestine, apparently to facilitate passage of digesta and possibly to facilitate digestion (Ulyatt et al. 1975). These authors defined flow of digesta in the large intestine as intermittent and variable, and although feeding appeared to affect motility, the regulation of digesta flow remains poorly understood. Retention times for digesta have been reported as 10-29 $\mathrm{h}$ with much of that time in the caecum; however, we have observed some components of digesta transversing the entire (small and large) intestine of sheep in only 6-7 h. We believe that passage rate and function of the large intestine is the principal factor affecting faecal form and the incidence of dags in sheep. We are aware of a range of factors which are associated with an increased incidence of dags (Table 3 ) and hypothesise that these (parasite larval challenge, intestinal worms, fungal endophyte, etc.) either increase the rate of passage through the large intestine, or reduce the capability of the large intestine to absorb water, both of which will result in loose faeces able to form dags. However, even when endophytes and worms are not present, substantial variation can occur between individuals. For example, when young sheep were given a dried and pelleted pasture based diet (indoors) some individuals were able to form pellets when faecal DM was as low as $23 \%$, but others did not form pellets when faecal DM was 32\% (Waghorn et al. 1994; Wesselink et al. 1995). Hence moisture content will effect the incidence of dags when faeces are loose (e.g., Fletcher \& Sutherland 1993) but when faeces are formed into pellets the moisture content appears to be of little significance (e.g., Leathwick \& Atkinson 1996).

Table 3 Factors contributing to dagginess in sheep.

Gastrointestinal parasites (roundworms)
Species and site of infection (abomasum, small, large
intestine)
Worm numbers
Intestinal mucous secretion
Parasite larval challenge
Ingestion of larvae, previous exposure, "resistance"
Fungal endophytes
Concentration of endophyte in herbage
Type of endophyte/active agents
Diet/Physiological state
Level of intake, feed quality, grazing horizons (which
affects intake of parasite larvae or fungal endophyte)
Lactation/late pregnancy resulting in rapid passage of
digesta
Body condition; poor condition/poor nutrition
Susceptibility to toxins/parasites
Combined effects (e.g., larval challenge with endophyte)
Tail length, rear end anatomy, wool length
Changing diets, grain feeding can encourage diarrhoea
Other toxins affecting increased smooth muscle activity
Other

\section{Initiation and formation of dags}

The agents responsible for initial adhesion of faeces to wool need to be defined, as well as factors responsible for the spread and accumulation of faeces. We have 
indicated the importance of faecal form, in so far as pellets do not adhere to wool whereas sloppy faeces or diarrhoea adheres readily, but we need to understand reasons why diets containing condensed tannins (lotuses, sulla; Leathwick \& Atkinson 1995, 1996; Robertson et al. 1995) result in low dag scores whilst pasture with similar concentration of fibre, protein and of a similar digestibility can result in extensive dags. Other variables which might affect adhesion include water content (aside from faecal form), presence of mucus, serum (a consequence of parasite damage to the mucosa) fungal toxins (from pasture endophyte) as well as mineral content resulting from disturbances in large intestinal function. In order that these factors could be evaluated, we developed a method for testing faecal adhesion in a repeatable, rapid and operator independent manner.

The techniques involved either dragging wool across a faecal sample or rolling wool in a faecal sample. In both cases, we used long (120 mm staple) fleece wool either attached to the underside of a small sled, which was dragged across test faeces, or wrapped around a half tube, which was weighted and rocked back and forth in faeces. All procedures were repeated 3, 9 or 18 times enabling the initial adhesion ( 3 times) to be evaluated separately from progressive accumulation of faeces (9 or 18 times).

Problems associated with this type of test include the substantial variation in the form of faeces requiring evaluation (pellets to diarrhoea) and the relatively small proportion of faecal production that actually accumulates as dags. If a standard sheep consumes $1.2 \mathrm{~kg} \mathrm{DM} /$ day with a digestibility of $70 \%$, then output of faecal DM will be $360 \mathrm{~g} /$ day, $2.5 \mathrm{~kg} /$ week and $130 \mathrm{~kg}$ per annum. However if faeces comprise $75 \%$ water, then the respective amounts of wet material will be 1.4, 10.1 and $525 \mathrm{~kg}$. Accumulation as dags on sheep with a worm burden and fed pasture are only 2-20 g DM/week (Leathwick \& Atkinson 1995; Robertson et al. 1995) so at most, only about $1 \%$ of faeces is caught up in the wool and the annual accumulation of dags is probably closer to $0.1 \%$ of faecal output. The proportion of faeces becoming dags is therefore small, but with significant implications.

Table 4 summarises the effects of a range of variables on faecal adhesion to wool. Whilst addition of serum to faeces did reduce adhesion (for reasons we do not understand) virtually every addition or alteration to faecal composition made matters worse - inevitably because mixing altered the fine structure of the faeces. Diet per se did not affect adhesion, unless through production of pellets rather than loose material and there were no effects of urine or wool type on adhesion. Hence we believe faecal form on both a macro scale (pellets, stools, diarrhoea) and micro scale (effects of mixing, homogenising, i.e., rapid and extensive mixing, adding water, etc.) have important implications for faecal adhesion. Intestinal function and especially the rate of passage through the large intestine, probably has the greatest influence on dag formation and future research needs to focus on this physiology and the way that known causes (and preventors) of dags affect the large intestine.

Table 4 Factors effecting adhesion of faeces to wool. All faeces tested were moist, without form and with a consistency between stools and diarrhoea. Unpublished data.

\begin{tabular}{|c|c|}
\hline Test & Effect on adhesion ${ }^{a}$ \\
\hline Temperature of faeces & no effect \\
\hline Urine stain on wool & no effect \\
\hline Cut ends vs long staple ${ }^{b}$ & no difference \\
\hline Merino vs crossbred & no difference \\
\hline \multicolumn{2}{|l|}{ Faecal type: } \\
\hline contrasting diets & no effect with faeces of similar type \\
\hline caecal contents vs faeces & caecal contents extremely adhesive \\
\hline \multicolumn{2}{|l|}{ Additions: } \\
\hline water & greater increase in adhesion than \\
\hline & $\begin{array}{l}\text { expected, perhaps due to physical } \\
\text { effects of homogenising }\end{array}$ \\
\hline serum & reduced adhesion \\
\hline fibre particles & increased adhesion \\
\hline mineral elements & inconsistent increases \\
\hline detergent & increased adhesion \\
\hline Ianolin & no effect \\
\hline gums & substantial increase \\
\hline Contrasting fresh forage diets & no effect with faeces of a similar type \\
\hline \multicolumn{2}{|c|}{$\begin{array}{l}\text { a no distinction is made between adhesion of faeces to wool or to } \\
\text { faeces. }\end{array}$} \\
\hline \multicolumn{2}{|c|}{$\begin{array}{l}\text { b long staple refers to the tests of adhesion to wool mid way along the } \\
\text { staple vs. adhesion to cut ends of wool as in a crutched sheep. }\end{array}$} \\
\hline
\end{tabular}

\section{Causes of dags}

While a very small proportion of faecal production ends up as dags, a much higher proportion may potentially cause dags; it just doesn't stick. Whilst faecal consistency is the principal factor influencing dag production, other influences might include tail length, wool type/length and the physical anatomy of the sheep rear end (perhaps affected by breed). Simple observations show that during defecation, the faeces often brush against wool below the anus. With pelleted faeces this does not result in any build up on the wool, but stools and loose faeces do leave a thin coating on the wool. Some sheep wiggle their tails during defacation and this can either disperse pellets, or smear loose faecal material over a wider area. This accumulation of dags is highly correlated with flystrike $\left(r^{2}=0.97\right.$; Leathwick \& Atkinson 1995) and the accumulation of dags is reduced by docking (French et al. 1994a). We are not aware of published data documenting lengths of docked tails (e.g., $5,10,15 \mathrm{~cm}$ ) on the extent of dag formation in crossbred sheep 
although docking to a very short stub does increase the incidence of flystrike (French et al. 1994b).

Other aspects of anatomy, or actions of defecation which might reduce dags (e.g., standing or squatting during defecation, as distinct from defecation whilst lying down, which is common in some sheep) do not appear to have been documented. Data do not appear to be available to indicate differences (if any) between male and female sheep, nor are data available which define the importance of wool growth and distribution in the breech area, or the effects of amount and type of wool on the incidence of dags.

Although anatomy and wool cover may affect dags, the principal factor influencing their incidence is faecal consistency and some factors leading to loose or liquid faeces have been summarised in Table 3. When considering the causes of loose or liquid faeces, it is also important to consider the amount of time an animal produces non-pelleted faeces, and whether a short period of scouring could result in a substantial accumulation of dags. For example, if 5\% of faeces adhered to wool, then an animal having loose faeces on 3-4 occasions over a week might build up a large accumulation of dags even though it normally produced pellets or firm stools. Tests of adhesion did show that a very rapid build up of faeces on wool was possible, and this will be made worse by lying in dung.

Parasitism (intestinal nematodes or roundworms) is most often considered the principal causative agent of dags, but lack of discrimination between parasitism and fungal endophytes in many previous trials may have underestimated the significance of endophyte. For example, Eerens et al. (1992) reported higher levels of dags in sheep grazing endophyte infected pasture than endophyte free pasture. This has been confirmed in reports of increased scouring and dags in sheep consuming forage with Acremonium lolli (Fletcher \& Sutherland 1993) and by Pownall et al. (1993) who reported faecal water contents of $80-87 \%$ in sheep grazing infected ryegrass compared with $68 \%$ in adjacent pasture. In a recent article, Fletcher (1999) showed flystrike affected $8 \%$ of sheep grazing endophyte free pastures compared with $35 \%$ in lambs grazed on endophyte infected pasture.

Nematodes undoubtedly contribute to scouring, but a survey of causes of dagginess in sheep (Wesselink et al. 1995) showed larval challenge to be more important than worm burden per se. Furthermore, worm burdens are not necessarily indicated by faecal egg count (FEC) and this may account in part for conflicting reports. For example, McEwan et al. (1992) showed a positive correlation between loose faeces and dag score $(\mathrm{r}=0.54)$ and between FEC and dag score $(\mathrm{r}=0.62)$, yet Morris et al. (1997) reported that lambs selected for low FEC had
$41 \%$ more soiling (dags) than lambs selected for high FEC. Under an identical larval challenge, the lambs with high FEC also produced $15 \%$ more wool than these selected for low FEC and McEwan et al. (1992) found total FEC was strongly correlated with liveweight gain $(\mathrm{r}=0.95)$. Bisset et al. (1997) also reported that lambs selected for resistance to parasites (low FEC) had more dags and looser faeces than susceptible sheep. Hence the link between parasitism and dags is open to question, especially when parasitism is indicated by FEC, and there remains some debate about the effects of the hosts' immune response to ingestion of parasite larvae and the extent of dags (Leathwick \& Atkinson 1995).

Other factors associated with dags (Table 3 ) include high voluntary intakes and highly digestible pastures. Perhaps the lactating dairy cow provides the most graphic consequences of high intakes of lush pasture compared to growing animals fed poorer quality diet. Western (1988) showed the advancement of pregnancy increased faecal water by $72 \%$ whilst sheep given low intakes of a forage based (pelleted) diet produced faeces with a dry matter percentage of up to $49 \%$ (Wesselink et al. 1995). Level of intake affects the rate of passage through the intestines, and this in turn affects the composition of faeces and intestinal function. It would be interesting to measure effects of low $v$ s high intakes in sheep given forage with either endophyte or larval challenge. Another aspect of feed type and control of dags and worm numbers, concerns the use of forages containing condensed tannins (e.g., Waghorn et al. 1999). These forages (e.g., lotuses, sulla) have markedly reduced the incidence of dags and flystrike in sheep (Leathwick \& Atkinson 1995, 1996; Niezen et al. 1998) although their mode of action has not been clearly defined.

\section{Conclusion}

Dags are a widespread problem in the sheep flock, and their considerable cost to farmers is unlikely to be affected by selection of sheep having improved resistance to parasites. An additional cost associated with dags is an increased incidence of flystrike, which has been exacerbated by the recent arrival of the Australian Green blowfly (Lucilia cuprina). The "causes" of dags can be attributed to factors such as ingestion of fungal endophytes, larval challenge or worm burden but these are not directly responsible for dags; these factors affect intestinal function and this changes faecal characteristics in a way that facilitates faecal adhesion to wool and faeces. Comparisons of faecal types have shown that pelleted faeces and firm stools do not adhere to wool, but sloppy, loose faeces and diarrhoea is capable of extensive and rapid adhesion. Dags are therefore affected 
by large intestine function; this is probably a consequence of a rapid transit of digesta through this organ with insufficient absorption of water and failure to achieve a physical structure. Understanding of large intestinal physiology will greatly enhance our ability to reduce the incidence of dags, and this basic research should be afforded priority insofar as excellence in animal welfare must be a prerequisite to New Zealand's image as a producer of high quality foods. Dags and flystrike are the antithesis of animal care, cleanliness and quality.

\section{ACKNOWLEDGEMENTS}

Parts of the work cited here were funded by Wool New Zealand and Meat New Zealand. Thanks also to Drs Ken Geenty, Allen Heath and to Robin Kidd for helpful advice.

\section{REFERENCES}

Bisset, S.A.; Vlassoff, A.; West, C.J.; Morrison, L. 1997. Epidemiology of nematodosis in Romney lambs selectively bred for resistance or susceptibility to nematode infection. Veterinary parasitology 70 : 255-269.

Eerens, J.P.J.; Ryan, D.L.; Miller, K.B. 1992. The ryegrass endophyte in a cool moist environment. Proceedings of the New Zealand Grassland Association 54: 157-160.

Fletcher, L.R.; Sutherland, B.L. 1993. Flystrike and faecal contamination in lambs grazing endophyte infected ryegrass. Second international symposium on Acremonium/grass interactions, 122-124. Palmerston North.

Fletcher, L. 1999. Pasture discovery. New Zealand Farmer April 291999.

French, N.P.; Wall, R.; Morgan, K.L. 1994a. Lamb tail docking: a controlled field study of the effects of tail amputation on health and productivity. The veterinary record 134: 463-467.

French, N.P.; Wall, R.; Morgan, K.L. 1994b. Tail docking of lambs in the control of flystrike. The veterinary record 135: 47.

Heath, A.C.G.; Bishop, D.M. 1995. Flystrike in New Zealand. Surveillance 22(2): 11-12.

Larsen, J.W.A.; Anderson, N.; Vizard, A.L.; Hoste, G.A. 1994. Diarrhoea in merino ewes during winter: association with trichostrongylid larvae. Australian veterinary journal 71: 365-372.

Leathwick, D.M.; Atkinson, D.S. 1995. Dagginess and flystrike in lambs grazed on Lotus corniculatus or ryegrass. Proceedings of the New Zealand Society of Animal Production 55: 196-198.
Leathwick, D.M.; Atkinson, D.S. 1996. Influence of different proportions of Lotus corniculatus in the diet of lamb on dags, flystrike and animal performance. Proceedings of the New Zealand Society of Animal Production 56: 99-102.

Mackereth, V.J. 1983. Dags-cost thereof. Proceedings of the New Zealand Society of Animal Production 43: 231.

McEwan, J.C.; Mason, P.; Baker, R.L.; Clarke, J.N.; Hickey, S.M.; Turner, K. 1992. Effect of selection for productive traits on internal parasite resistance in sheep. Proceedings of the New Zealand Society of Animal Production 52: 53-56.

Morris, C.A.; Vlassoff, A.; Bisset, S.A.; Baker, R.L.; West, C.J.; Hurford, A.P. 1997. Responses of Romney sheep to selection for resistance or susceptibility to nematode infection. Animal science 64: 319-329.

Niezen, J.H.; Robertson, H.A.; Waghorn, G.C.; Charleston, W.A.G. 1998. Production, faecal egg counts and worm burdens of ewe lambs which grazed six contrasting forages. Veterinary parasitology 80 : $15-27$.

Pownall, D.B.; Lucas, R.J.; Familton, A.S.; Love, B.G.; Fletcher, L.R. 1993. Endophyte associated mycotoxins and diarrhoea in lambs. Second International Symposium on Acremonium/grass interactions, 132-134. Palmerston North.

Pullman, A.L.; Beveridge, I.; Martin, R.R. 1991. Effects of challenge with trichostronglylid nematode larvae on immunologically resistant grazing yearling sheep in South Australia. Veterinary parasitology 38: 155162.

Robertson, H.A.; Niezen, J.H.; Waghorn, G.C.; Charleston, W.A.G.; Jinlong, M. 1995. The effect of six herbages on liveweight gain, wool growth and faecal egg count of parasitised ewe lambs. Proceedings of the New Zealand Society of Animal Production 55: 199-201.

Ulyatt, M.J.; Dellow, D.W.; Reid, C.S.W.; Bauchop, T. 1975. Structure and function of the large intestine of ruminants. pp. 119-133. In: Digestion and metabolism in the ruminant. Eds. McDonald, I.W.; Warner, A.C.I. Armidale, University of New England Publishing Unit.

Waghorn, G.C.; Black, H; Horsbrugh, T.H. 1994. The effect of salt and bentonite supplementation on feed and water intake, faecal characteristics and urine output in sheep. New Zealand veterinary journal 42: 24-29.

Waghorn, G.C.; Reed, J.D.; Ndlovu, L.R. 1999. Condensed tannins and herbivore nutrition. pp. 153156. In: Proceedings of the XVIII International Grasslands Congress, Volume III. Eds. Buchanan- 
Smith, J.C.; Bailey, L.D.; McCaughey, P. Calgary $\mathrm{AB}$, Association Management Centre.

Wesselink, R.; Waghorn, G.C.; McNabb, W.C. 1995.

Causes of dagginess in sheep. A survey of the literature undertaken for Wools of New Zealand. Palmerston North, AgResearch Grasslands.

Western, R.H. 1988. Factors limiting the intake of feed by sheep. XI. The effect of pregnancy and early lactation on the digestion of medium quality roughage. Australian journal of agricultural research 39: 659-669. 
